\title{
Geographic information system-based identification of suitable cultivation sites for wood-cultivated ginseng
}

\author{
Mu Sup Beon ${ }^{1}$, Jun Ho Park ${ }^{2}$, Hag Mo Kang ${ }^{3}$, Sung Jong Cho ${ }^{4}$, and Hyun Kim ${ }^{4 *}$ \\ ${ }^{1}$ Department of Landscape Architecture, Chonbuk National University, Jeonju 561-756, Korea \\ ${ }^{2}$ Gyeongsangnam-do Forest Environment Research Institute, Jinju 660-871, Korea \\ ${ }^{3}$ Department of Forest Environmental Science, Chonbuk National University, Jeonju 561-756, Korea \\ ${ }^{4}$ Jeollabuk-do Forest Environment Research Institute, Jinan 567-883, Korea
}

Wood-cultivated ginseng, including roots in its dried form, is produced in forest land without using artificial facilities such as light barriers. To identify suitable sites for the propagation of wood-cultivated ginseng, factor combination technique (FCT) and linear combination technique (LCT) were used with geographic information system and the results were superimposed onto an actual wood-cultivated ginseng plantation. The LCT more extensively searched for suitable sites of cultivation than that by the FCT; further, the LCT probed wide areas considering the predominance of precipitous mountains in Korea. In addition, the LCT showed the much higher degree of overlap with the actual cultivation sites; therefore, the LCT more comprehensively reflects the cultivator's intention for site selection. On the other hand, the inclusion of additional factors for the selection of suitable cultivation sites and experts' opinions may enhance the effectiveness and accuracy of the LCT for site application.

Keywords: Panax ginseng, Wood-cultivated ginseng, Geographic information system, Suitable site of cultivation

\section{INTRODUCTION}

Wood-cultivated ginsengs are perennial plants that are semi-heliophobic and commonly used in Chinese medicine. Due to their extensive medicinal effects, they are widely cultivated in China, Korea, and Hong Kong; the cultivation area and production of ginseng are steadily increasing every year [1]. Historically, wild ginseng cultivation started in the period of the Three States, and continued during the Koryo Dynasty with wood-cultivation, followed by ginseng farming in the Chosun Dynasty [2].

Recently, the Korea Forest Service (KFS) defined wood-cultivated ginseng as ginseng (including dried ginseng) propagated in forest land without the use of any artificial facilities such as light barriers [3]. It is very difficult to search for suitable sites for wood-cultivation of

cc This is an Open Access article distributed under the terms of the Creative Commons Attribution Non-Commercial License (http://creativecommons.org/licenses/by-nc/3.0/) which permits unrestricted non-commercial use, distribution, and reproduction in any medium, provided the original work is properly cited. ginseng in forest land; the use of geographic information system (GIS) as an alternative to searching for suitable cultivation sites can thus serve as an effective solution.

Suitable cultivation sites for various crops such as ginseng [4], garlic [5], red pepper [6], Rubus coreanus (Korean black raspberry) [7], Schisandra chinensis [8], mulberry [9], and apple [10] have been recently identified using GIS. However, sites for wood-cultivated ginseng have not been conducted. In addition, most of the studies or searches for suitable plantations are limited to the use of the factor combination technique (FCT) on zonal overlaps or area analysis on the extracted suitable areas using the linear combination technique (LCT) [11].

This study embarked on employing the FCT and the

Edited by Young Ho Kim, Seoul National University, Korea

Received 26 Mar. 2013, Revised 27 Jul. 2013, Accepted 01 Aug. 2013

*Corresponding author

E-mail: kh4548@korea.kr

Tel: +82-63-290-5452, Fax: +82-63-290-5512 


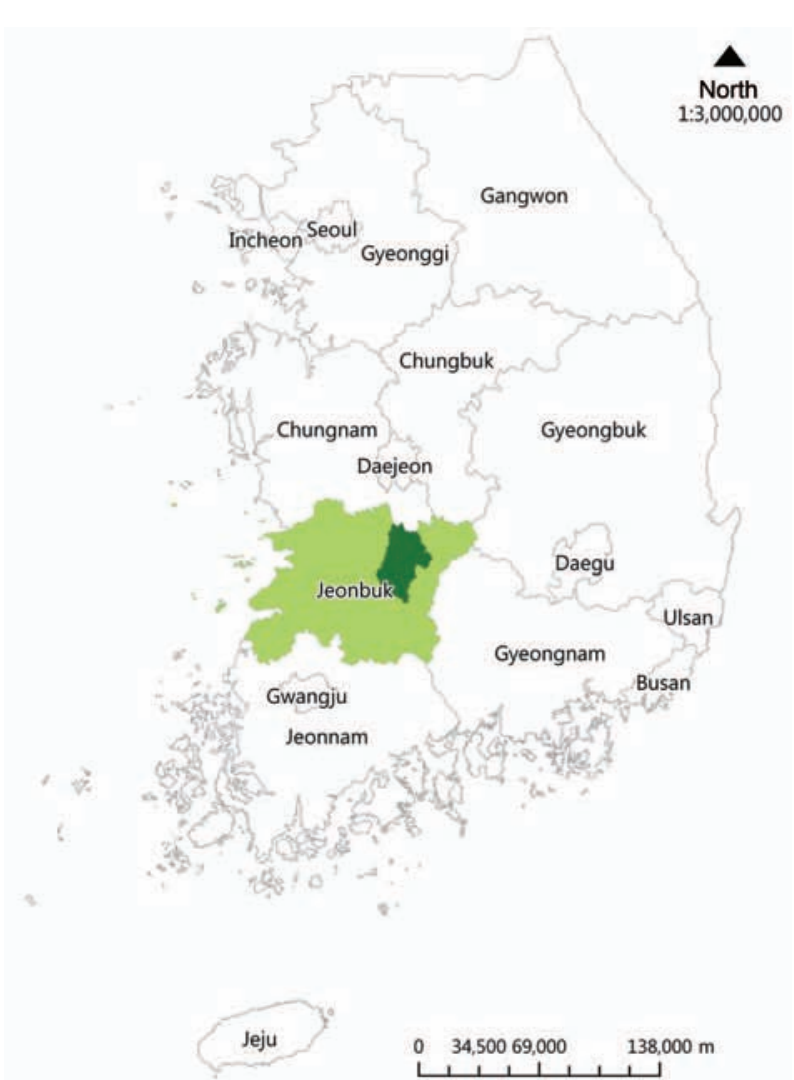

Fig. 1. Research area of this study. Jinan-gun (green color) is located in the eastern mountain range of Jeollabuk-do (Jeonbuk).

LCT with GIS to search for the suitable sites for woodcultivated ginseng in the forests, and the results were subjected to overlap analysis to provide a more effective way of identifying sites of propagation.

\section{MATERIALS AND METHODS}

\section{Research area}

This research was conducted by targeting the forests of Jinan-gun, Jeollabuk-do. Jinan-gun is located in the eastern mountain range of Jeollabuk-do, with geographical coordinates: N $35^{\circ} 49^{\prime}-\mathrm{N} 36^{\circ} 39^{\prime}$, E $127^{\circ} 16^{\prime}$-E $127^{\circ} 37^{\prime}$ (Fig. 1). Its area is $789.09 \mathrm{~km}^{2}$, the second largest region in Jeollabuk-do; $79.9 \%$ of the region consists of forests. As seen from its large forest area, Jinan-gun is one of the locations in South Korea that produces various forest products such as ginseng, Shiitake mushrooms, and the bellflower Codonopsis lanceolata [12].

\section{Factor selection for suitable cultivation site search}

To search for suitable sites for wood-cultivated ginseng using GIS, several growth factors were selected based on the results of previous studies and a survey of farmhouses.

\section{Data processing}

Data on suitable propagation sites for the propagation of wood-cultivated ginseng were processed using a topographic map $(1: 25,000)$ and the KFS's forest type map (5th ed.) and forest soil map. After generating triangulated, irregular network data through contour extraction, the altitude, aspect, and slope were processed as gridshaped raster data (30Í30 m) to create a topographic map. In addition, data regarding forest type (species), organic contents, effective soil depth, soil texture, humidity, and drainage were processed as raster data by using an attribute database of the forest type map and forest soil map.

The information on wood-cultivated ginseng cultivation locations (53 sites) obtained through a survey of farmhouses was used to produce a database.

\section{Search for the suitable cultivation sites}

A search for the suitable cultivation sites was conducted by using the FCT and LCT in combination with GIS. While the FCT is easy to apply and understand, its workload can increase if several factors are used. In terms of the LCT, depending on the relative importance of factors, inappropriate sites can be included in the search results $[7,11]$.

This study analyzed suitable cultivation sites using 2 techniques: the sites were categorized into 4 grades; suitable, possible, contemplative, and unsuitable [9], based on the Jenks Natural Breaks Classification method [13]. In addition, the degree of overlap of each search technique was determined by comparing the raster data processed through extracting searched suitable areas with the data of wood-cultivated ginseng sites by using zonal statistics methods. ArcMap 10 by ESRI (Redlands, CA, USA) was used for suitable cultivation area search.

\section{RESULTS}

\section{Factors for suitable cultivation sites}

Previous reports have shown that altitude, aspect, slope, forest type (species), organic content, effective soil depth, soil texture, soil humidity, and drainage are important factors that affect the cultivation of wood-cultivated ginsengs [14-19]. Weighted values were assigned to the factors by subdividing specific conditions per suitable sites factor and applying these to the FCT and LCT (Table 1).

\section{Search of suitable sites for wood-cultivated gin- seng}

Suitable sites for cultivation were identified by ap- 
Beon et al. Identification of suitable cultivation sites

Table 1. Factors and weighted values for searching suitable cultivation sites

\begin{tabular}{|c|c|c|c|}
\hline \multirow{2}{*}{ Factor } & \multirow{2}{*}{ Condition } & \multicolumn{2}{|c|}{ Weighted value } \\
\hline & & FCT & LCT \\
\hline \multirow[t]{2}{*}{ Altitude } & More than $300 \mathrm{~m}$ & 1 & 1 \\
\hline & Others & 0 & 0.5 \\
\hline \multirow[t]{3}{*}{ Aspect } & North & 1 & 1 \\
\hline & East, northeast, northwest & 0 & 0.67 \\
\hline & Others & 0 & 0.33 \\
\hline \multirow[t]{2}{*}{ Slope } & Less than $30^{\circ}$ & 1 & 1 \\
\hline & Others & 0 & 0.5 \\
\hline \multirow{3}{*}{ Forest type (species) } & Hardwood forest, Larix leptolepis & 1 & 1 \\
\hline & Mixed forest & 0 & 0.67 \\
\hline & Others & 0 & 0.33 \\
\hline \multirow[t]{2}{*}{ Organic content } & Between 2\% and 9\% & 1 & 1 \\
\hline & Other & 0 & 0.5 \\
\hline \multirow{2}{*}{ Effective soil depth } & More than $15 \mathrm{~cm}$ & 1 & 1 \\
\hline & Others & 0 & 0.5 \\
\hline \multirow[t]{2}{*}{ Soil texture } & Sandy loam, loam, silty clay loam & 1 & 1 \\
\hline & Others & 0 & 0.5 \\
\hline \multirow[t]{2}{*}{ Soil humidity } & Suitable humidity & 1 & 1 \\
\hline & Others & 0 & 0.5 \\
\hline \multirow[t]{2}{*}{ Drainage } & Good condition & 1 & 1 \\
\hline & Others & 0 & 0.5 \\
\hline
\end{tabular}

FCT, factor combination technique; LCT, linear combination technique.

A

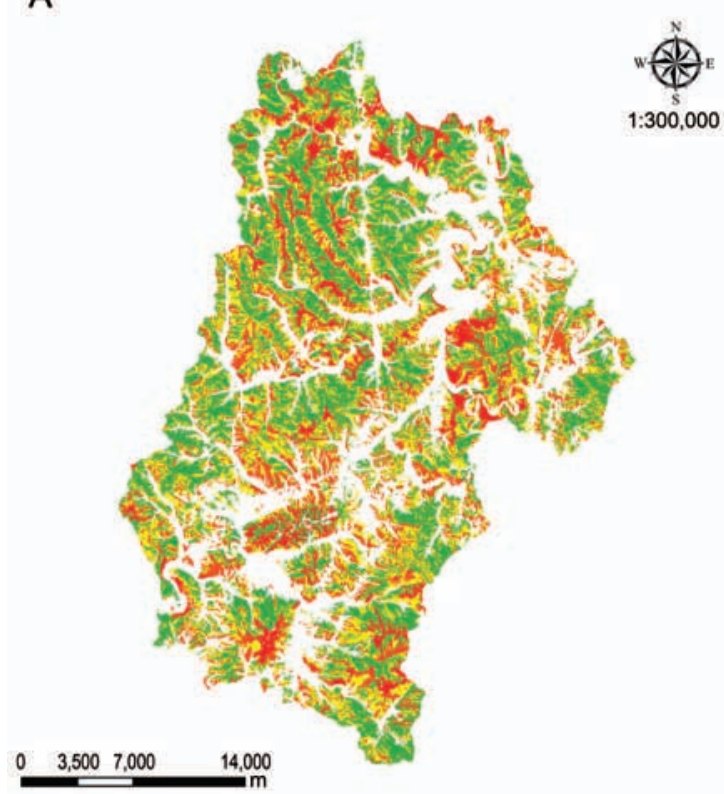

Table 2. Search results for suitable cultivation sites by using 2 techniques

\begin{tabular}{lcccc}
\hline Technique & $\begin{array}{c}\text { Suitable } \\
\text { site }\end{array}$ & $\begin{array}{c}\text { Possible } \\
\text { site }\end{array}$ & $\begin{array}{c}\text { Contemplative } \\
\text { site }\end{array}$ & $\begin{array}{c}\text { Unsuitable } \\
\text { site }\end{array}$ \\
\hline FCT & $22,337(40.2)$ & $17,907(32.3)$ & $11,061(19.9)$ & $4,196(7.6)$ \\
LCT & $28,328(51.1)$ & $21,408(38.6)$ & $4,323(7.8)$ & $1,429(2.6)$ \\
\hline
\end{tabular}

Values are presented as ha (\%).

FCT, factor combination technique; LCT, linear combination technique.

plying weighted values that correspond to the specific conditions of each factor to the respective raster database (Fig. 2). Using the FCT, the search results were as follows: a suitable area of 22,337 ha (40.2\%), possible area of 17,907 ha (32.3\%), contemplative area of 11,061 ha (19.9\%), and unsuitable area of 4,196 ha (7.6\%). On the other hand, according to the LCT, the results were as follows: a suitable area of 28,328 ha (51.1\%), possible area of 21,408 ha (38.6\%), contemplative area of 4,323 ha (7.8\%), and unsuitable area of 1,429 ha (2.6\%) (Table 2).

The results of the 2 techniques were layer-extracted and the data were analyzed through zonal statistics. Among the suitable areas detected by the FCT, the overlapped area with wood-cultivated ginseng plantation data was 263.88 ha; and among suitable areas by the LCT, the overlapped area with wood-cultivated ginseng plantation data was 328.23 ha. The degree of overlap (b/a) of real cultivation area (a) with the results (b) of the FCT and LCT was $44.1 \%$ and $54.8 \%$, respectively; the results of
B

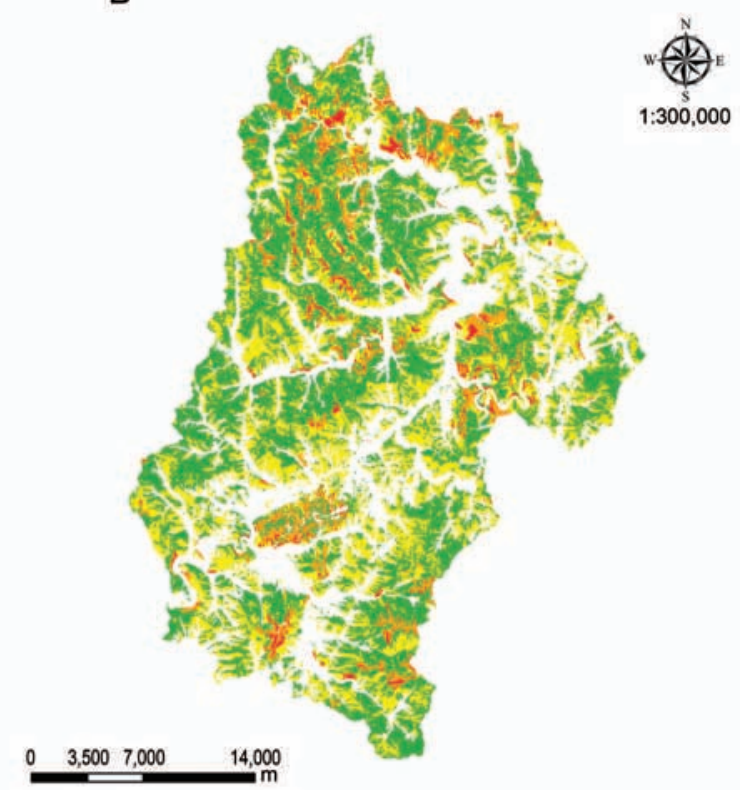

Fig. 2. Suitable cultivation sites searched by using factor combination technique (A) and linear combination technique (B). Green color, yellow color, orange color, and red color show suitable site, possible site, contemplative site, and unsuitable site, respectively. 
Table 3. Zonal statistical analysis result

\begin{tabular}{cccc}
\hline Technique & $\begin{array}{c}\text { Real area } \\
\text { (a, ha) }\end{array}$ & $\begin{array}{c}\text { Overlapped Area } \\
\text { (b, ha) }\end{array}$ & $\begin{array}{c}\text { Overlap ratio } \\
\text { (b/a, \%) }\end{array}$ \\
\hline FCT & 599.03 & 263.88 & 44.1 \\
LCT & 599.03 & 328.23 & 54.8 \\
\hline
\end{tabular}

FCT, factor combination technique; LCT, linear combination technique.

the LCT showed a higher degree of overlap (10.7\%) than that generated by the FCT (Table 3).

\section{DISCUSSION}

Search analysis of suitable wood-cultivated ginseng plantations by utilizing GIS with FCT and LCT showed that wider areas were detected by the LCT than the FCT. This result may be attributable to the fact that more forest lands were selected as suitable sites according to the relative importance of the factors [7,11].

Comparison of the actual cultivation area and the suitable area detected by the 2 techniques showed that the LCT generated a greater area of overlap compared to that using FCT. This was not only because the LCT detected wide areas as suitable but also because it can be interpreted in terms of suitable site selection. Further, the LCT data comprehensively reflected the wood-cultivated ginseng growers' opinions on the propagation of woodcultivated ginseng.

In the case of Korea, where forest lands are steep and rough and accessibility is poor, it will be ideal to use LCT to search for suitable wood-cultivated ginseng plantations so that wider areas can be detected; full consideration can be given to environmental and natural characteristics to identify a specific cultivation area.

On the other hand, a major merit of this study compared with recent studies [20,21], which identified the factors for suitable cultivation sites as quantitative indicators by analyzing the sites for wood-cultivated ginseng, lies in the fact that it presented a method for searching suitable sites for wood-cultivated ginseng applicable to the geographical conditions of Korean forest land using GIS as well as the quantitative factors for suitable cultivation sites. However, despite the advantages of this convenient GIS-based scientific method for identifying suitable sites, the accuracy of the site detection results should be cited as a limitation. Thus, there may be a need to include additional factors for the selection of suitable cultivation sites such as location, soil, and climate to raise the accuracy of the search using GIS. Hence, a system should be structured to easily utilize various GIS data- bases at the national level. Also, the input of field experts such as researchers and farmers may also be integrated in the search for suitable sites by applying an analytic hierarchy process that reasonably assesses weighted values of each factor and maximizes the accuracy of the search $[7,9]$.

\section{ACKNOWLEDGEMENTS}

This paper was supported by research funds of Chonbuk National University in 2009.

\section{REFERENCES}

1. Forest Research Institute of Gangwon Province. Study by Forest Research Institute of Gangwon Province. In: Lee SJ, Kim HK, Shin DY, eds. Study on wood-cultivated ginseng by producing area. Chuncheon: Gyeongmun Press, 2012. p.72.

2. Korea Forestry Promotion Institute. Cultivation and management skills for wild edible greens and wood-cultivated ginseng. In: Kang JH, ed. Characteristics and cultivation skills for wood-cultivated ginseng. Seoul: Ridrik Press, 2013. p.79.

3. Statutory information: instruction, regulation, and notification. Available from: http://forest.go.kr/newkfsweb/cop/ bbs/selectBoardArticle.do?nttId=2310109\&bbsId=BBSM STR_1005\&pageUnit=10\&pageIndex $=1 \&$ searchtitle=titl e\&searchcont $=\&$ searchkey $=\&$ searchwriter $=\&$ searchWrd $=\%$ ec $\% 82 \%$ b0 $\%$ ec $\% 96 \% 91 \%$ ec $\% 82 \%$ bc\& $\&$ tgryLrcls $=\&$ ctgryMdcls $=\&$ ctgrySmcls $=\& n t c S t a r t D t=\& n t c E n d D t=\& m$ n=KFS_06_03_04.

4. Kim YY. Selection to be compatible site for ginseng information system in Kumsan area. J Ginseng Res 2002;26:24-30.

5. Kim YW, Jang MW, Hong SY, Kim YH. Assessing southern-type garlic suitability with regards to soil and temperature conditions. Korean J Soil Sci Fertil 2012;45:266271.

6. Jung SJ, Bark BS, Jang GS, Hyun BK, Rim SK. Suitability class criteria for red pepper cultivation with respect to soil morphology and physical properties. Korean J Soil Sci Fertil 2004;37:336-340.

7. Kim TJ, Lee GS. The site analysis for crop cultivation using GIS-based AHP method. J Korean Soc Civ Eng 2006;26:695-702.

8. Kim H, Kim HJ, Choi SM, Lee SH. A GIS-based analysis for suitable site of Schisandra chinensis cultivation: focused on Jangsu County forest. J Agric Life Sci 2011;45:41-47. 
9. Kim H, Kim HJ, Choi SM, Kang HM, Lee SH. Detection of suitable sites for effective cultivation of Morus alba L. J Agric Life Sci 2012;46:9-16.

10. Kim SO, Chung U, Kim SH, Choi IM, Yun JI. The suitable region and site for 'Fuji' apple under the projected climate in South Korea. Korean J Agric For Meteorol 2009;11:162-173.

11. Jo MH, Kim JB, Jo YW, Baek SR. Application method of satellite image and GIS for suitability of black locust forest as honey plant area. J Korean Assoc Geogr Inf Stud 2001;4:27-37.

12. Basic statistics: statistical yearbook. Available from: http://www.jinan.go.kr/board/view.sko?boardId=ADb01 \&boardSid=14\&menuCd=MM04002001000\&contentsSi $\mathrm{d}=115 \&$ orderBy $=$ dataTitle:asc\&startPage=1\&searchType $=\&$ keyword $=\&$ searchStartDt $=\&$ searchEndDt $=\&$ category Code $1=1209971050800 \&$ categoryCode $2=\&$ categoryCod e $3=\&$ dataSid $=31106$

13. Sanyal J, Lu XX. Application of GIS in flood hazard mapping: a case study of Gangetic West Bengal, India. In: Proceedings of Map Asia Conference; 2003 Oct 1315; Kuala Lumpur, Malaysia. Kuala Lumpur: Geospatial Media and Communications, 2003.

14. Korea Forest Research Institute. Cultivation and management skills for forest medicinal herbs. Seoul: Usgomunhwa Press, 2010.
15. Lee IH, Yuk CS, Han KW, Park CS, Park HS, Nam KY. Influence of various soil characteristics in ginseng field on the growth and the yield of ginseng (Panax ginseng C. A. Meyer). Korean J Ginseng Sci 1980;4:175-185.

16. Ministry for Agriculture and Forestry. Management model of ginseng growing in the forest. Gwacheon: Ministry for Agriculture and Forestry, 1998.

17. Mork SK, Son SY, Park H. Root and top growth of Panax ginseng at various soil moisture regime. Korean J Crop Sci 1981;26:115-120.

18. Seo SM. Eco-physiological characteristics and ingredient differences of forest ginseng in various forest environments [dissertation]. Seoul: University of Seoul, 2010.

19. Woo SY, Lee DS. A study on the growth and environments of Panax ginseng in the different forest stands (I). Korean J Agric For Meteorol 2002;4:65-71.

20. Han H, Seo SM, Suh HM, Lee DS, Chung JS. Analyzing the environment of cultivation sites of mountain ginseng in Gyeongbuk Province using a discriminant function. In: Proceedings of the 2011 Joint Conference on Forest Science. Seoul: Korean Forest Society, 2011. p.472-475.

21. Yang BH, Yoo CY, Jeong JY, Choo GC, Kim CS, Lim JT, Lee SL. Site characteristics of mountain-cultivated ginseng in Hamyang-gun, Gyeongsangnam-do. In: Proceedings of the 2010 Annual Meeting of the Korean Forest Society. Seoul: Korean Forest Society, 2010. p.89-91. 